\title{
The influence of soft clay saturation characteristics on unconfined compressive strength in Guangdong-Hong Kong-Macao Greater Bay Area
}

\author{
DaShu Guan ${ }^{1,2, a}$, JiaXi Zheng ${ }^{1}$, WenHao Huang ${ }^{*}$, JunZhi Zhong ${ }^{1}$, WenWen Du' ${ }^{1}$, ZhiDe Luo ${ }^{1}$, and YinShi Zhou ${ }^{1}$ \\ ${ }^{1}$ Guangdong Polytechnic of Water Resources and Electric Engineering, Guangzhou, Guangdong 510925, China \\ ${ }^{2}$ State Key Laboratory for Geomechanics \& Deep Underground Engineering, China University of Minding and Technology, Xuzhou, \\ Jiangsu221116, China
}

\begin{abstract}
In order to study the influence of saturated characteristics of soft clay on unconfined compressive strength, the soft clay of Guangdong-Hong Kong-Macao Bay Area is taken as the research object, comparing and contrasting on unconfined compression test of saturated clay and unsaturated clay in laboratory, studying the variation law of unconfined compressive strength and sensitivity of unsaturated and saturated soft clay. The test results show that: 1. During the failure of unsaturated soft clay samples, oblique fractures appear, showing brittle shear failure, while the saturated clay samples appear constant bulging in the middle, and finally a "cross" is broken in the central bulging part, showing plastic shear failure.2. The unconfined compressive strength of unsaturated clay is about $10 \mathrm{kPa}$ higher than that of saturated soft clay, and its corresponding sensitivity is also about 0.4 higher. It can be shown that the soil saturation has a certain influence on the soil strength. The difference between saturated soil and unsaturated soil is the existence of gas phase. To be more precise, the existence of gas phase in unsaturated soil, i.e. the existence of suction, makes the soil stronger and presents the brittle shear failure form, while the saturated soil basically presents the plastic shear failure form.
\end{abstract}

\section{Introduction}

Saturated soil has only two phases, i.e. solid phase and liquid phase (i.e. soil particles and water); unsaturated soil is generally recognized as four phases, namely solid phase (soil particles), liquid phase (water), gas phase (air) and shrinkage membrane (water air interface). The saturation of saturated soil is 1 , and that of unsaturated soil is less than 1. Therefore, the two can convert each other, exhausting all the gas in saturated soil, so that the saturation becomes 1, that is to say, saturated soil. However, the water in the saturated soil is drained away, and the air enters into the soil, which makes the unsaturated soil become. Therefore, there are differences and connections between the two. Due to the existence of gas phase in unsaturated soil, the properties of soil are more complex than that of saturated soil. For the convenience of engineering research, most researchers will consider using saturated soil to do the experiment. Because the influence of gas and water air interface can be excluded in saturated soil, it can be regarded as a kind of ideal soil, so the research theory of saturated soil is also better Comprehensive improvement. However, the research on unsaturated soil is less. As a common soil in nature, the study of unsaturated soil is also considered from the aspects of deformation, strength and seepage.
However, due to the existence of suction, the soil condition is more complex. And suction is part of the gas phase.

Suction is an important parameter of unsaturated soil properties and an important stress variable to characterize unsaturated soil properties. It is the premise and foundation of unsaturated soil properties research. The total suction of soil consists of matrix suction and osmotic suction. The matric suction is mainly affected by the change of soil water content or saturation, and the osmotic suction is mainly affected by the change of salt content. It is also an important factor affecting the strength characteristics of unsaturated soil. Domestic and foreign scholars have studied the influence of suction on the engineering properties of unsaturated soil ${ }^{[1 \sim 3]}$. Toll ${ }^{[4]}$ proposed to separate the total stress and matrix suction to consider its shear effect on unsaturated soil, which also proved that the matrix suction affects the shear strength of soil through some transformation. Domestic scholars have also proved this idea through various indoor experiments [5 6] . Through unconfined compressive strength test, Jinfeng $\mathrm{Li}^{[7]}$ proved that water and salt have influence on the permeability and suction of unsaturated soil.

Unconfined compressive strength test is an important index of soil mechanical properties ${ }^{[8]}$.

In this paper, the soft clay in Guangdong, Hong Kong and Macao Bay area is taken as the research object. 
Through the indoor unconfined compressive strength test, the stress-strain curve, unconfined compressive strength and sensitivity of saturated clay and unsaturated clay are obtained respectively to explore the difference of unconfined compressive strength between saturated clay and unsaturated clay. The results are expected to promote the further understanding of gas phase in soil, and promote the further development of saturated soil mechanics.

\section{Sample preparation}

\subsection{Test materials}

The test soil samples were collected from the soft clay of Shanwei and Foshan in Guangdong, Hong Kong and Macao Bay area respectively. The basic physical parameters of the soil were determined according to the standard for soil test methods. The results of the basic parameters are shown in Table 1.

Table1. Basic physical parameters of soil samples.

\begin{tabular}{cccccccc}
\hline $\begin{array}{c}\text { test } \\
\text { number }\end{array}$ & $\begin{array}{c}\text { Density } \\
/ \mathrm{g} \cdot \mathrm{cm}^{2}\end{array}$ & $\begin{array}{c}\text { natural water } \\
\text { content } \\
/ \%\end{array}$ & proportion & $\begin{array}{c}\text { liquid limit } \\
/ \%\end{array}$ & $\begin{array}{c}\text { plastic } \\
\text { limit } \\
/ \%\end{array}$ & $\begin{array}{c}\text { cohesive } \\
\text { force } \\
/ \mathrm{kPa}\end{array}$ & $\begin{array}{c}\text { internal friction } \\
\text { angle } \\
\rho^{\circ}\end{array}$ \\
\hline $14 \#$ & 1.689 & 53.38 & 2.641 & 56.98 & 33.61 & 19.76 & 16.22 \\
$21 \#$ & 1.625 & 53.37 & 2.639 & 59.18 & 34.43 & 19.24 & 16.54 \\
B 区 & 1.694 & 53.40 & 2.637 & 48.09 & 28.61 & 12.37 & 12.30 \\
$25-1$ & 1.685 & 46.78 & 2.646 & 53.48 & 31.21 & 14.75 & 18.10 \\
$25-2$ & 1.682 & 46.92 & 2.643 & 53.54 & 31.17 & 14.70 & 18.06 \\
$2 \mathrm{~K}-24$ & 1.673 & 30.55 & 2.647 & 47.69 & 27.72 & 9.40 & 23.50 \\
\hline
\end{tabular}

\subsection{Test scheme}

Six triaxial soil samples were made by remolding cylinder, and then three of them were extracted and saturated to make saturated soil samples. Then, the unconfined compressive strength and its corresponding sensitivity are calculated according to the experimental data, and the stress-strain curve is drawn.

\subsection{Test procedure}

In this unconfined compressive strength test, the strain controlled unconfined pressure gauge was used to make the original soil into a triaxial soil sample with a diameter of $39.1 \mathrm{~mm}$ and a height of $80 \mathrm{~mm}$. The axial strain rate should be $1 \% \sim 3 \%$ per minute. When the axial strain is less than $3 \%$, read once every $0.5 \%$ strain (or $0.4 \mathrm{~mm}$ ), read once every $1 \%$ strain (or $0.8 \mathrm{~mm}$ ) when the axial strain is equal to or greater than $3 \%$. The test should be completed within $8 \sim 10 \mathrm{~min}$.

Measurement sensitivity, the damage will be immediately after the specimen to remove the surface of the coated with vaseline, add a few more than soil, pack in the plastic film with the hand rub knead, its structure, reshape into cylindrical, into the cylinder is reshaping, with metal plate sample to squeeze into equal sample and undisturbed sample size, density, and test according to the above steps.

\subsection{Data processing and calculation}

The axial strain of the specimen is as follows:

$$
\varepsilon_{1}=\frac{\Delta h}{h_{0}}
$$

Average sample area:

$$
A_{a}=\frac{A_{0}}{1-0.01 e_{1}}
$$

Axial stress of specimen:

$$
\sigma=\frac{C R}{A_{a}} \times 100
$$

Sensitivity:

$$
\varepsilon_{t}=\frac{q_{u}}{q_{u}^{\prime}}
$$

\section{Analysis of test results}

\subsection{Data sorting}

The data measured from the test were substituted into the above formula to calculate the relevant data of unearthed samples respectively. The following are 6 classic samples, as shown in Table 2. 
Table2. Unconfined compression test data of soil samples.

\begin{tabular}{ccccc}
\hline $\begin{array}{c}\text { Soil sample } \\
\text { number }\end{array}$ & category & $\begin{array}{c}\text { Undisturbed soil unconfined } \\
\text { compressive strength } q_{u} / \mathrm{kPa}\end{array}$ & $\begin{array}{c}\text { The remoulded unconfined } \\
\text { compressive strength } q_{u}^{\prime} / \mathrm{kPa}\end{array}$ & sensitivitys \\
\hline $14 \#$ & Unsaturated soil sample & 28.25 & 9.51 & 2.97 \\
$21 \#$ & Unsaturated soil sample & 25.67 & 9.98 & 2.57 \\
B 区 & Unsaturated soil sample & 21.36 & 7.54 & 2.83 \\
$25-1$ & Saturated soil sample & 9.10 & 4.06 & 2.24 \\
$25-2$ & Saturated soil sample & 7.66 & 1.85 & 2.15 \\
$2 \mathrm{~K}-24$ & Saturated soil sample & 11.86 & 7.49 & 1.58 \\
\hline
\end{tabular}

Then the corresponding stress-strain curve is obtained by fitting software according to the recorded data of the test.

Figure 1 to Figure 6 are the stress-strain curves of the soil sample, in which (1) is the unaltered soil sample and (2) is the remolded soil sample:

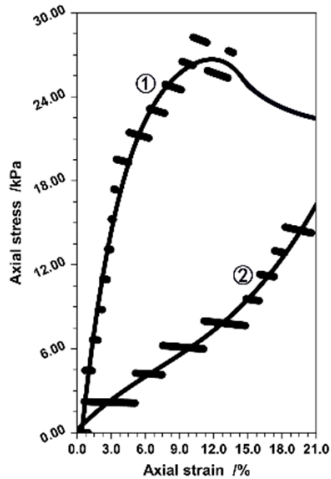

Fig.1. Sample no.14 unsaturated soil.

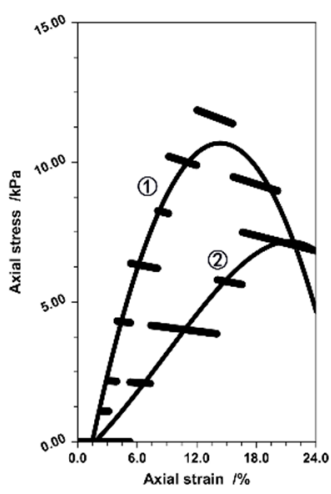

Fig. 3. Unsaturated soil saturated sample in area B.

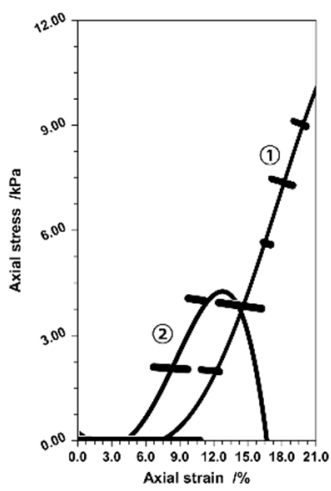

Fig.5. Sample of saturated soil.

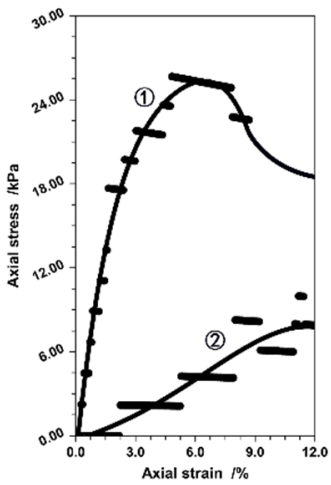

Fig.2. Sample no. 21 unsaturated soil

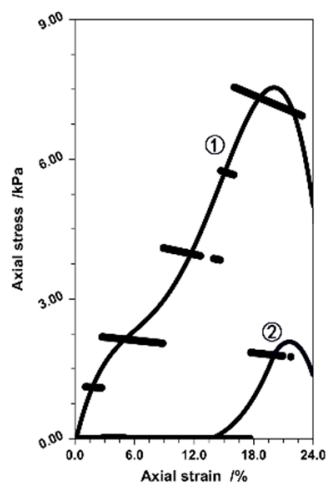

Fig. 4. Sample no No. 2-2 saturated soil.

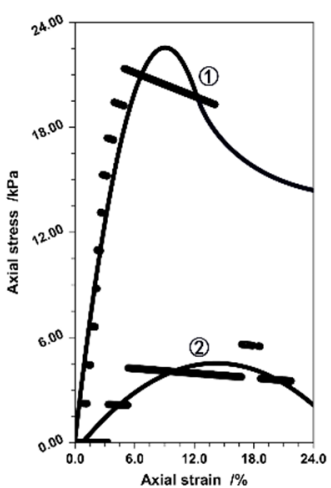

Fig.6. 2K-24 soil sample.

\subsection{Analysis of Results}

From 6 set of test data record and finishing in table 2, can see intuitive unsaturated undisturbed soil and remolded soil unconfined compressive strength than saturated undisturbed soil and remolded soil higher than that of the unconfined compressive strength of around $10 \mathrm{kPa}$, and its corresponding sensitivity is high, about 0.4 or so, which can explain the soil saturation and a certain influence on the strength of the soil moisture content. Both of the stress-strain curves fitted by the fitting software showed strain softening type with only peak strength, and both of them had a steep rise stage at the early stage of axial strain change, then experienced a peak, and finally experienced a steep fall stage after the peak. The difference is that the peak stage of the soil sample of unsaturated soil appears earlier than that of saturated soil, and the axial stress of unsaturated soil sample is generally about $17 \mathrm{kPa}$ higher than that of saturated soil.

\subsection{Failure mode}

The failure results of each soil sample after unconfined test are shown in the figure below.

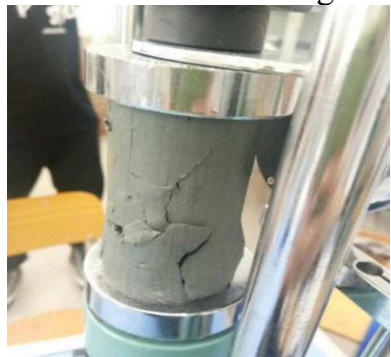

Fig.7. 14\# Failure of undisturbed soil.

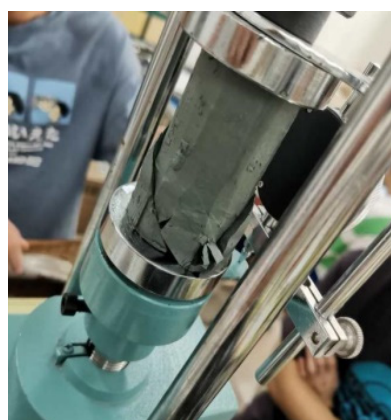

Fig.9. 21\# Destruction of undisturbed soil.

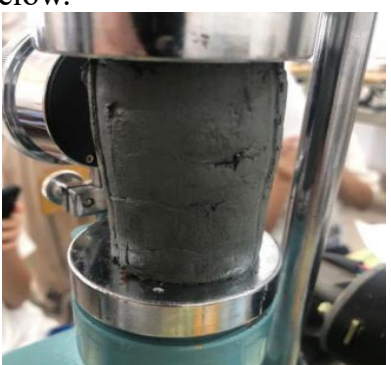

Fig.8. 14\# Reshaped soil destruction.

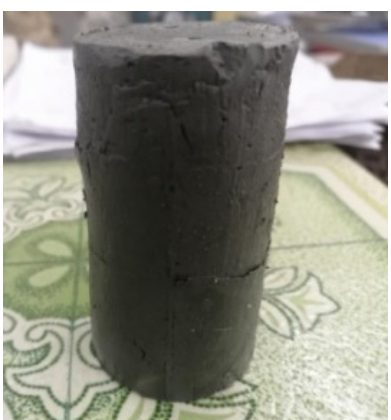

Fig.10. 21\# Reshaped soil destruction. 


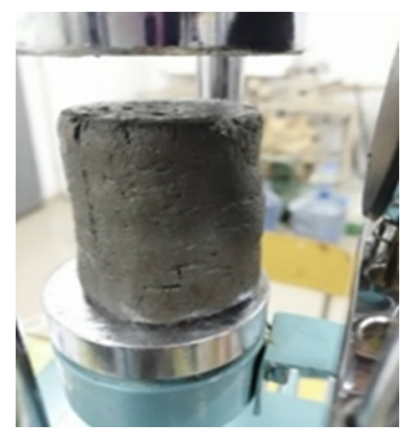

Fig.11. 25-1 Failure undisturbed soil.

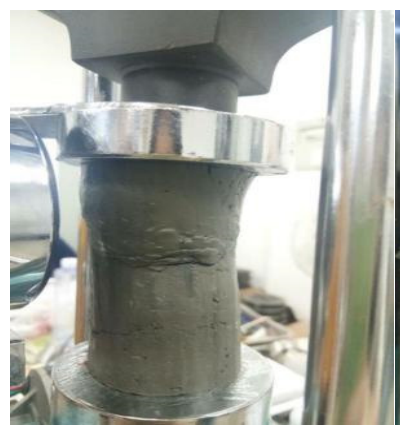

Fig.13. 25-2 Failure of undisturbed soil.

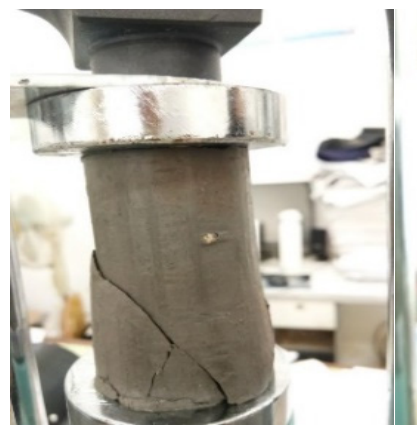

Fig.15. Failure of undisturbed soil in Area B.

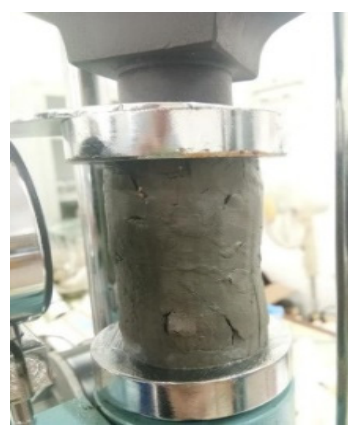

Fig.17. Damage of 2K-24 undisturbed soil.

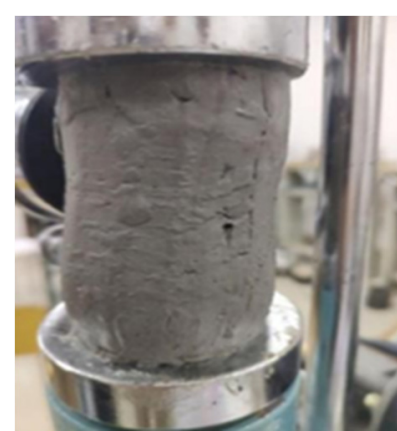

Fig.12. 25-1Remodeled soil destruction.

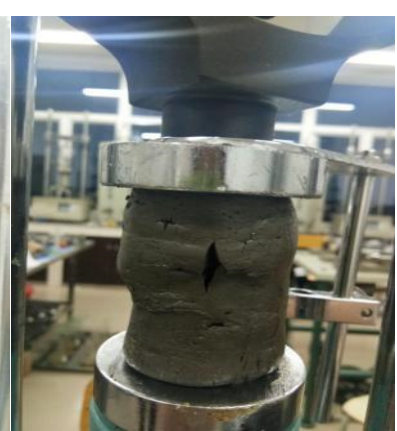

Fig.14. 25-2 Remolded soil destruction.

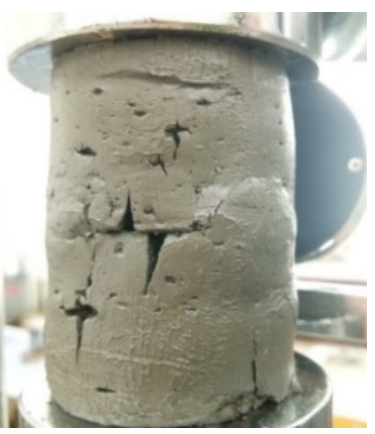

Fig.16. Remolded soil failure in Area B.

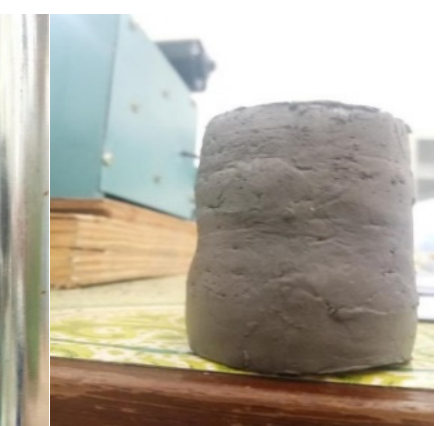

Fig.18. 2K-24 remolded soidamage.

\section{Conclusion}

Unsaturated soil by extraction after becoming saturated soil in the saturated, unconfined strength of the soil cut relatively than the original by about $10 \mathrm{kpa}$, sensitivity and relatively low around 0.4 , existing in the research results show that in the unsaturated soil sample was particle pore in the extraction of gas saturation after most of the displacement into water, the soil strength is relatively weak. More specifically, the presence of suction in the soil is relatively higher than the strength of the soil sample filled with water in the pores, that is, the presence of gas phase in the unsaturated soil, that is, the presence of suction, has a certain influence on the strength of the soil. The presence of suction makes the soil stronger.

\section{About the author}

* First author: DaShu Guan (1983 -), male, PhD, senior engineer, mainly engaged in research and design of engineering geology, composite foundation and geological disaster prevention. Mobile :15913142403 ; * Corresponding author: WenHao Huang (2001 -), male, mainly engaged in research of engineering geology and foundation treatment. Mobile: 13421528577;

\section{Funded by the following funds:}

1. Guangdong Polytechnic of Water Resources and Electric Power (cy0604zk06);

2. Scientific Research innovation Platform of Guangdong Polytechnic of Water Resources and Electric Power (cy0603yz02);

3. Special Fund for Science and Technology Innovation Strategy of Guangdong Province (Special Fund for "Climbing Plan", pdjh2021b0812).

\section{References}

1. Hongzhou Lin, Guangxin Li, Yuzhen Yu, et al. The influence of matrix suction on shear resistance of unsaturated soil [j]. Geotechnical mechanics, 2007, 28 (09): 1931-1936.

2. Kun Huang, Junwei Wan, Gang Chen, et al. Experimental study on the relationship between shear strength and water content of unsaturated soil [J]. Geotechnical mechanics, 2012, 33 (09): 2600-2604.

3. Qianling Meng, Hailin Yao, Lunfeng Qiu. Contribution of suction to shear strength of unsaturated soil [J]. Geotechnical mechanics, 2001, 22 (04): 423-426 + 431.

4. Toll D G. A framework for unsaturated soil behaviour[J]. Géotechnique, 1990, 40(1): 31-44.

5. Haotian Guo. Study on frost heaving failure mechanism of deep foundation pit in seasonal frozen area based on triaxial test of unsaturated soil [D]. Jilin Jianzhu University, 2018.

6. Tao Li, Bo Liu, Weihong Yang, et al. Experimental study on the influence of matrix suction on shear strength of remolded red clay [J]. Journal of China University of mining and technology, 2013,42 (03): 375-381. [77].

7. Jinfeng Li. Experimental study on influence of water and salt on suction and unconfined compressive strength of unsaturated soil [D]. Jilin University, 2020 . 
8. Nanjing Institute of water resources research. Standard of soil test method: GB/T50123-1999 [S]. Beijing: China water resources and Hydropower Press, 1999:14-16.

9. Yuhan Li. Experimental study on influence of water content and clay content on strength of unsaturated soil [D]. East China Jiaotong University, 2014.

10. Ning Lu, William, J. likos, unsaturated soil mechanics [M], June 2015, higher education pres. 